\title{
Preterm birth: associated risk factors and outcome in tertiary care center
}

\section{Mamatha B. Shetty*, Krupa B. M., Mounica Malyala, Asha Swarup, Davis Sabu Pathadan, Suneha Pocha}

Department of Obstetrics and Gynecology, Ramaiah Medical College, Bangalore, Karnataka, India

Received: 08 June 2017

Revised: 04 July 2017

Accepted: 14 July 2017

\section{*Correspondence:}

Dr. Mamatha B. Shetty,

E-mail: drmamathabshetty@gmail.com

Copyright: (c) the author(s), publisher and licensee Medip Academy. This is an open-access article distributed under the terms of the Creative Commons Attribution Non-Commercial License, which permits unrestricted non-commercial use, distribution, and reproduction in any medium, provided the original work is properly cited.

\section{ABSTRACT}

Background: The major cause of infant mortality and morbidity is preterm birth. WHO has defined it as any birth before 37 completed weeks of gestation or fewer than 259 days since the last day of menstrual period. Objective of present study was to identify major etiological factors associated with preterm birth, and their effects on mode of delivery and neonatal mortality and morbidity.

Methods: Retrospective cohorts study, which was conducted in M. S. Ramaiah Medical College, over period of 12 months (January 2015 to December 2015). The study included 343 women who delivered preterm they were followed from admission to discharge. Various parameters were analyzed like maternal characteristics, gestational age, associated risk factors, tocolysis, administration of steroids, and neonatal outcome.

Results: The incidence of preterm birth among the total deliveries was approximately $18.01 \%$. Although the risk factors included many, the most common occurring were hypertensive disorders during pregnancy approximately $32.9 \%$, followed by preterm rupture of membranes (18.1\%), idiopathic $14.9 \%$, and previous LSCS at $12.2 \%$. Neonatal mortality was $6.9 \%$ (24 neonates), and stillborn were $0.5 \%$ ( 2 neonates).

Conclusions: Various risk factors for preterm labour are modifiable hence early detection and treatment prevents maternal morbidity and neonatal morbidity and mortality. Specific emphasis on regular antenatal checkups.

Keywords: Hypertensive disorders in pregnancy, Neonatal mortality, Preterm birth, Previous LSCS

\section{INTRODUCTION}

The major cause of infant mortality and morbidity is preterm birth. WHO has defined it as any birth before 37 completed weeks of gestation or fewer than 259 days since the last day of menstrual period. $60 \%$ of preterm birth occurs in developing countries such as Africa and South Asia and rest of the world contributes to $40 \%$ of preterm, hence having a impact globally. ${ }^{1}$ India is one among ten countries with the greatest preterm neonates. ${ }^{2}$
Availability and accessibility to health care is a major problem which effects outcome of various diseases in developing countries. Whereas in developed countries preterm birth is attributed to other causes such as, increase in usage of infertility drugs due to late marriages leading to usage of artifical reproductive techniques. And increased in late conception and psychological stress in working women, drug abuse, smoking. $40-75 \%$ of neonatal deaths are contributed by developing countries, whereas in developed countries it effects 1 in 10 births. ${ }^{3}$ 
Approximately three-fourth of the perinatal deaths occur in fetus that delivered at $<37$ weeks, and $40 \%$ among these delivered at $<32$ weeks. In addition to its contribution to mortality, preterm birth is one of the cause for cerebral palsy and other neurodevelopemental functions such as impaired learning and visual disorders and leading to long term morbidity like risk of chronic disease of adulthood. ${ }^{4}$

Hence there is need to identify risk factors associated preterm birth, in means to provide improved health care facilities for preterm neonates along with mothers.

\section{METHODS}

Retrospective cohorts study, conducted in M.S Ramaiah Medical College and Hospital, Bangalore. Data was obtained from January 2015 to December 2015, approval for the study was taken from the Institutional Ethics Committee. The patient records and details were obtained from the medical records department from the case file. The prefix proforma was made to which includes these parameters like parity index, gestational age, and diagnosis, and mode of delivery, along with baby details, these parameters further analyzed. Deliveries which occurred in our institution from gestational period between 28 to 37 weeks, were included in this study. The total number of deliveries among this period was 1904 of which 343 were preterm deliveries equating to approximately $18.01 \%$.

Women with regular cycles, the gestational age was calculated using Neagle's formula and women with irregular cycle, age of fetus was confirmed with dating scan done in first trimester. The proforma used was data entry included information of mother, medical history, current pregnancy details, baby details, previous conceptions, medical disorders during pregnancy, and investigations. Risk factors found were categorized: PROM, medical disorders, anemia, hypothyroidism, hyperthyroidism, malpresentation, multiple pregnancy, oligohydramnions/ polyhydramnios, diabetes, previous history of cesarean section, hypertensive disorders.

Frequency, percentage, univariate analysis, were used for analytic inference. Analysis was done using SPSS Statistical Software package.

\section{RESULTS}

Total 1904 number of deliveries occurred during the above-mentioned period, 343 patients delivered were preterm, approximately $18.01 \%$.

As Table 2 demonstrates, that nearly half $(55.7 \%)$ of the preterm were 32-36 weeks of gestation. On further analysis of all the risk factors associated with preterm births, as mentioned in Table 4 , the following were the top 4 causes of preterm births, number one being hypertension during pregnancy approximately $32.9 \%$, followed by preterm rupture of membranes (18.1\%), idiopathic $14.9 \%$, and previous LSCS at $12.2 \%$.

Table 1: Maternal factors.

\begin{tabular}{|lll|}
\hline Factors & No. of cases & $\%$ \\
\hline Maternal Age & & \\
\hline$<20$ years & 30 & 8.7 \\
\hline $20-24$ years & 97 & 28.3 \\
\hline $25-29$ years & 151 & 44.0 \\
\hline $30-35$ & 46 & 13.4 \\
\hline$>35$ & 19 & 5.5 \\
\hline Parity Index & & \\
\hline Primigravida & 146 & 42.6 \\
\hline Multigravida $>2$ & 197 & 57.4 \\
\hline
\end{tabular}

Table 2 Gestational period.

\begin{tabular}{|lll|}
\hline Gestational age in weeks & No. of deliveries & $\%$ \\
\hline 28-32 weeks & 72 & 20.9 \\
\hline $32-36$ weeks & 191 & 55.7 \\
\hline$>36$ weeks & 80 & 23.3 \\
\hline
\end{tabular}

Majority of the pregnancy were vaginal deliveries (55.7\%), of which $66 \%$ were spontaneous deliveries. As this is a tertiary referral center the number LSCS conducted are in hospital were approximately $44.3 \%$ this is attributed to increase in the number of referred case in view high risk pregnancy and for good neonate care.

Table 3: Mode of delivery.

\begin{tabular}{|lll|}
\hline Mode & No. of cases & $\%$ \\
\hline Vaginal & 191 & 55.7 \\
\hline Induced & 65 & 34.0 \\
\hline Spontaneous & 126 & 66.0 \\
\hline LSCS & 152 & 44.3 \\
\hline
\end{tabular}

Among the various risk factors, it was observed that hypertension complicating pregnancy was major cause of preterm birth, most mothers associated with severe preeclampsia was medical induced preterm birth, in order to decrease the risk of eclampsia and its complication.

Preterm rupture of membranes is the next leading cause of preterm birth, tocolysis was given to about 10 cases $(16 \%)$ in order to allow time for betamethasone action. In our center 51 case $(14.9 \%)$, no medical cause of preterm labour was identified, which may be attributed to maternal physical and/or psychological stress.

Approximately $44.3 \%$ of the preterm deliveries conducted in our hospital were LSCS, which may be attributed to various risk factors, such as previous LSCS (12.2\%), malpresentation (8.2\%), uterine scar dehiscence $(1.5 \%)$, multiple gestation $(4.9 \%)$, placenta praevia $(2.3 \%)$. The neonatal mortality and morbidity has significantly reduced due increased medical advancements. $66.5 \%$ (228) of the newborns were 
admitted to the NICU either for observation for prematurity and various other complications like perinatal asphyxia, respiratory distress syndrome, and spesis. Among the preterm births 42 neonates (12.24\%) were intrauterine growth restriction. Neonatal mortality in NICU was 24 neonates $(6.9 \%)$, and stillborn were 2 $(0.5 \%)$. The risk of respiratory distress syndrome was significantly reduced due to 2 doses of bethametasone.

Table 4: Risk factors associated with preterm birth.

\begin{tabular}{|lll|}
\hline Risk factors & No. of cases & $\%$ \\
\hline Anemia & 10 & 2.9 \\
\hline $\begin{array}{l}\text { Hypertension during } \\
\text { pregnancy }\end{array}$ & 113 & 32.9 \\
\hline $\begin{array}{l}\text { Preterm rupture of } \\
\text { membranes }\end{array}$ & 62 & 18.1 \\
\hline Gestational diabetes mellitus & 13 & 3.8 \\
\hline Infections & 15 & 4.4 \\
\hline Antepartum hemorrhage & 9 & 2.6 \\
\hline Placenta previa & 8 & 2.3 \\
\hline Multiple gestation & 17 & 4.9 \\
\hline Polyhydramnios & 4 & 1.2 \\
\hline Oligohydramnios & 29 & 8.5 \\
\hline Uterine Scar dehiscence & 5 & 1.5 \\
\hline History previous LSCS & 42 & 12.2 \\
\hline Cervical Incompetency & 3 & 0.9 \\
\hline Malpresentation & 28 & 8.2 \\
\hline Maternal cardiac disease & 3 & 0.9 \\
\hline Fetal distress & 2 & 0.6 \\
\hline Fetal anomaly & 5 & 1.5 \\
\hline Hypothyroidism & 34 & 9.9 \\
\hline Idiopathic & 51 & 14.9 \\
\hline
\end{tabular}

\section{DISCUSSION}

Preterm birth is truly a global problem as discussed above, the incidence of preterm birth is increasing in number, due to assisted reproductive techniques, maternal physical and psychological stress. The total number deliveries conducted over the period mentioned above, the preterm deliveries were total of $18.01 \%$. Preterm births are influenced by many factors, from maternal risk factors, pregnancy related complications, the social and environmental factors.

As we further discuss, extremes of maternal age play large role in preterm birth. Diallo et al study shows that preterm births at early age of conception $(7.95 \%)$ and late age of conception $(3.95 \%){ }^{6}$ In present study $8.7 \%$ of the patients were less 20 years of age, and $5.5 \%$ above 35 years as shown in Table 1.

Sonia Arogya et al study shows that multiparous women have higher chances at preterm delivery (72.92\%) whereas primigravida was $27.08 \%$, in our study we observed that there was 146 primigravida $(42.6 \%)$ and 197 mulitgravida $(57.4 \%)$ as depicted in Table 3 . $^{7}$
According to Cooper el al, study shows there is significant correlation between the number of previous abortion and its risk to preterm delivery, it states that multiparous patient has history of 1 abortion $(26.72 \%) .{ }^{8}$ In the study conducted in our hospital, fifty-seven women $(16.6 \%)$ had previous history of one abortion, whereas twenty -four $(6.9 \%)$ women had more than 2 abortions previously. Hence previous history abortion is also a risk factor for preterm births which correlates with EPIPAGE study. ${ }^{9}$

Carr-Hill and Hall state that there is $15 \%$ chance of preterm delivery with history one previous preterm delivery and $32 \%$ chance after 2 preterm delivery. ${ }^{10}$ In our study, twenty-two women $(6.4 \%)$ had previous history preterm labour. The commonest obstetrical risk factor in our study was hypertensive disorders of pregnancy $(32.9 \%)$ which shows similarity to Rao CR et al, in which hypertensive disorders accounted for $(21.4 \%) .{ }^{11}$ In present study, preterm rupture of membranes accounted for $18.1 \%$ were as in Van der Pool $30 \%$ were associated with rupture of membranes. ${ }^{12} 42$ women $(12.2 \%)$ with history of previous LSCS, in Divyakala et al they accounted for $25 \%$ with previous history of LSCS. ${ }^{13}$

The cause of delivery of 51 women (14. 9\%) of preterm delivery are idiopathic whereas Singh Uma et al $^{5}$ had $23.6 \%$, which may be attributed to maternal stress. Both in developed and developing countries preterm birth are unexplained. ${ }^{14}$

Table 5: Changing trends.

\begin{tabular}{|c|c|c|}
\hline Country & $\begin{array}{l}\text { Preterm } \\
\text { birth }\end{array}$ & Trends \\
\hline India (Singh Uma et al) $)^{5}$ & $20.9 \%$ & \\
\hline USA (Martin et al) $)^{15}$ & $12.3 \%$ & Increasing \\
\hline $\begin{array}{l}\text { United Kingdom (Bibby } \\
\text { and Stewart) }\end{array}$ & $7 \%$ & Increasing \\
\hline Australia (Robert et al) ${ }^{17}$ & $5.5 \%$ & Stationary \\
\hline Sweden (Morten et al) ${ }^{18}$ & $5-6 \%$ & Decreasing \\
\hline China (Leuing et al) ${ }^{19}$ & $7.4 \%$ & Increasing \\
\hline $\begin{array}{l}\text { Zimbabwe (Shingairai et } \\
\text { al) }\end{array}$ & $16.4 \%$ & Increasing \\
\hline Present study & $18.01 \%$ & \\
\hline
\end{tabular}

Data obtained from 184 countries, global average preterm birth rate was $11.1 \%$ in 2010 . Table 5 demonstrates the change trends globally. India has the highest preterm birth rate, around $13.0 \% .^{1,15-20}$ To reduces the incidence promotion of regular antenatal checkup and institutional deliveries.

\section{CONCLUSION}

Preterm birth is associated with various modifiable risk factors, providing proper education, preconceptional counseling and antenatal care will significantly reduce the incidence of preterm birth. The use of tocolysis, 
steroids prophylaxis, and antibiotics, along with timely referral to tertiary care, reduces the maternal morbidity and neonatal morbidity and mortality.

Funding: No funding sources

Conflict of interest: None declared

Ethical approval: The study was approved by the Institutional Ethics Committee

\section{REFERENCES}

1. Born too soon. The Global Action Report for Preterm Birth, MoD, PMNCH, Save the Children, WHO, New York, NY, USA;2012.

2. Blencowe H, Cousens S, Oestergaard M, Chou D, Moller AB, Narwal $R$ et al. National, regional and worldwide estimates of preterm birth. Lancet. 2012;379(9832):2162-72.

3. McPheeters ML, Miller WC, Hartmann KE, Savitz DA, Kaufman JS, Garrett JM, et al. The epidemiology of threatened preterm labor: a prospective cohort study. Am J Obstet Gynecol. 2005; $192 ; 1325-9$

4. Shrestha S, Dangol SS, Shrestha M, Shrestha RP. Outcome of preterm babies and associated risk factors in a hospital. J Nepal Med Assoc. 2010;50(180).

5. Singh Uma, Singh N, Seth S. A prospective analysis of etiology and outcome of preterm labor. J Obstet Gynecol India. 2007;57(1):48-52.

6. Diallo FB, Diallo MS, Sylla M, Diaw ST, Diallo TS, Diallo Y et al. Premature delivery - epidemiology, etiologic factors, prevention strategies. Dakar Med. 1998;43:70-3.

7. Prakash SA, Rasquinha S, Rajaratnam A. Analysis of Risk Factors and Outcome of Preterm Labor. Int J Eng Sci. 2016;2602.

8. Copper RL, Goldenberg RL, Creasy RK, DuBard MB, Davis RO, Entman SS et al. A multicenter study of preterm birth weight and gestational age specific neonatal mortality. Am J Obstet Gynecol. 1993; $168: 78$

9. Moreau C, Kaminski M, Ancel PY, Bouyer J, Escande B, Thiriez $G$ et al. Previous induced abortions and the risk of very preterm deliveryresults of EPIPAGE study. BJOG. 2005;112:430-7.
10. Carr-Hill RA, Hall MH. The repetition of spontaneous preterm labour. Br J Obstet Gynecol. 1985;92:921-8.

11. Von Der Pool BA. Preterm labor - diagnosis and treatment. Am Acad Fam Physician. 1998;57(10):2457-64.

12. Karegoudar D, Prabhu A, Amgain K, Dhital M. Perinatal outcome and associated maternal comorbid conditions in late preterm births-a prospective study at Kles Dr. Prabhakar Kore Hospital, Belgaum, India. Int J Curr Microbiol App. Sci. 2014;3(6):865-75.

13. Beck S, Wojdyla D, Say L, Betran AP, Merialdi M, Requejo $\mathrm{JH}$ et al. The worldwide incidence of preterm birth: a systematic review of maternal mortality and morbidity. Bulletin of the World Health Organization. 2010;88(1):31-8.

14. Martin JA, Kochanek KD, Strobino DM, Guyer B, MacDorman MF. Annual summary of Vital statistics - 2003. Pediatrics 2005;115:619-34.

15. Bibby E, Stewart A. The epidemiology of preterm birth. Neuroendocrinol. 2004;25 (Suppl 1):43-7.

16. Robert CL, Algert CS, Raynes GC, Peat B, Henderson-Smart DJ. Delivery of singleton preterm infants in New South Wales 1990-1997. Aust NZJ Obstet Gynecol. 2003;43:32-7.

17. Morten NH, Kallen K, Hagberg H, Jacobsson B. Preterm birth in Sweden 1973-2001. Rate, subgroups and effect of changing patterns in multiple births, maternal age and smoking. Acta Obstet Gynecol Scand. 2005;84:558-65.

18. Lening TN, Roach VJ, Lan TK. Incidence of preterm delivery in Hong Kong Chinese. Aust NZJ Obstet Gynecol. 1998;38:133-7.

19. Shingairai AF, Siobon DH, Godfrey BW. Risk factors for prematurity at Harare Maternity Hospital, Zimbabwe. Int J Epidemiol. 2004;33:1194-1201.

Cite this article as: Shetty MB, Krupa BM, Malyala M, Swarup A, Pathadan DS, Pocha S. Preterm birth: associated risk factors and outcome in tertiary care center. Int J Reprod Contracept Obstet Gynecol 2017;6:3271-4. 